\title{
Carbon Nanotube-Graphene hybrid: Recent Synthesis Methodologies and Applications
}

\author{
${ }^{1}$ Geoffrey Ijeomah, ${ }^{2}$ Fahmi Samsuri, ${ }^{3}$ Mohamad Adzhar Md Zawawi, ${ }^{4}$ Felix Obite \\ ${ }^{1,2}$ Faculty of Electrical \& Electronics Engineering, Universiti Malaysia Pahang, 26600 Pekan, Pahang, \\ Malaysia \\ ${ }^{3}$ School of Electrical \& Electronics Engineering, Universiti Sains Malaysia, 14300 Nibong Tebal, Penang, \\ Malaysia \\ ${ }^{4}$ Faculty of Electrical Engineering, Universiti Teknologi Malaysia, 81310 UTM Skudai, Johor, Malaysia \\ Iguijeomah2@gmail.com
}

\begin{abstract}
The melding of one-dimensional (1D) carbon nanotubes (CNTs) and two-dimensional (2D) graphene to generate a CNT-graphene hybrid with 3-dimensional (3D) features has generated a lot of scientific interest owing to the synergistic consequences of the resulting interface hybrid on the electrical, mechanical, electrochemical and optical properties, which presents plethora of opportunities in both fundamental research and device applications. The review presents an overview of the recent perspectives made in the field of CNT-graphene hybrid architectures. The possible applications particularly in device sensing, as well as challenges are also presented.
\end{abstract}

Indexed Terms- Carbon nanotubes, graphene, CNT-graphene hybrid, sensors

\section{INTRODUCTION}

Graphene - a one atom thick, $\mathrm{sp}^{2}$-hybridized 2D honeycomb lattice of carbon allotrope has opened up assortment of opportunities in the field of nanotechnology and materials science research. The extraordinary properties of graphene such as high electrical conductivity, electron transfer kinetics, quenching efficiency, high intrinsic mobility, good heat conductivity, high young modulus, good optical transmittance and high theoretical specific surface area have been exploited for various commercial and scientific applications [1-6].

However, the desire to address the limitations of individual graphene such as zero bandgap and challenges associated with functionalization, has triggered a new paradigm in which graphene is exploited as a scaffold platform to anchor other nanomaterials. To this end, CNTs with properties existing in the axial direction, can be well functionalized onto the exterior of graphene resulting in CNT-graphene hybrid with excellent out-of-plane properties. This transformation of 1D and 2D nanomaterials to $3 \mathrm{D}$ architectures expands the landscape of applications of nanomaterials, with potential applications in sensing [7], and energy [8-9], among others.

While the preparation of CNTs has dramatically advanced in recent times, the fabrication of graphene is still in its infancy. In general, graphene oxide (GO) is the preferred choice for hybridization with CNTs owing to its potential for mass production at reduced cost. However, solution synthesis requires the employment of functionalized or oxidized CNTs and reduced graphene oxide (rGO) which imposes convoluted chemical path with extreme toxic synthesis solvents and agents [10]. This can be overcome by synthesizing CNT-graphene hybrids via deposition of GO platelets from aqueous colloidal suspensions, followed by GO platelet-decorated metal catalyst particles on varying substrates during charge vapour deposition (CVD) synthesis [11]. While this dominant method is most advantages for CNT-graphene synthesis, an efficient and facile method for direct hybridization of CNTs and graphene nanomaterials remains a huge challenge for nanoelectronic research.

In this review, we present various facets relevant to nanoscale architecture of CNT-graphene hybrid fabrication methods. This is followed by comprehensive discussion of novel applications of 
CNT-graphene hybrid interface junction, while highlighting the challenges of banding two nanoscale materials with different dimensionalities and interface alignments. The review concludes with a brief look into the future of CNT-graphene hybrid engineering.

\section{SYNTHESIS OF CNT-GRAPHENE HYBRID}

Several synthesis methods have been developed for fabricating CNTs since its isolation by Iijimma [12]. The comprehensive overview of properties, synthesis and applications of CNTs can be found here [13]. For its part, graphene can be synthesized via any of mechanical exfoliation, CVD, thermal reduction, thermal decomposition, exfoliation and reduction-oxidation (redox) processes. For comprehensive review on the preparation and synthesis techniques, readers are directed to the following literature [14]. Recently, various methodologies have been invented to synthesize CNTgraphene hybrid, which include hybridization of graphene and CNTs architectures [15], and layer-bylayer stacking [16]. Some recently invented synthesis methods for CNT-graphene hybrids are discussed in this section.

\subsection{Layer-by-layer (LBL) assembly}

The assembly of functionalized CNT-graphene hybrid takes advantage of the respective functionalities of individual materials or uncomplicated solvent wetting method. Hong et al. [16] reported LBL hybridization of positively charged CNTs sandwiched between oppositely charged rGO sheets via electrostatic interaction. LBL hybridization offers numerous fundamental advantages. First, it ensures unvarying dispersion of CNTs into the composite, which is made possible via direct adsorption of CNTs from a solution to a solid phase eliminating the need for phase segregation. Second, the LBL assembly is simple, offering robust processibility for large scale production of CNTgraphene hybrid via control of appropriate experimental parameters. Third, hybrid composites with precisely controlled multi-component nano-layers possess tunable multifunctional characteristics. The challenges of dispersion of CNTs in polymer composites were conquered by the pioneering work of Zheng et al. [17-18]. Figure 1 illustrates LBL hybridization via electrostatic interactions of the reacting species.
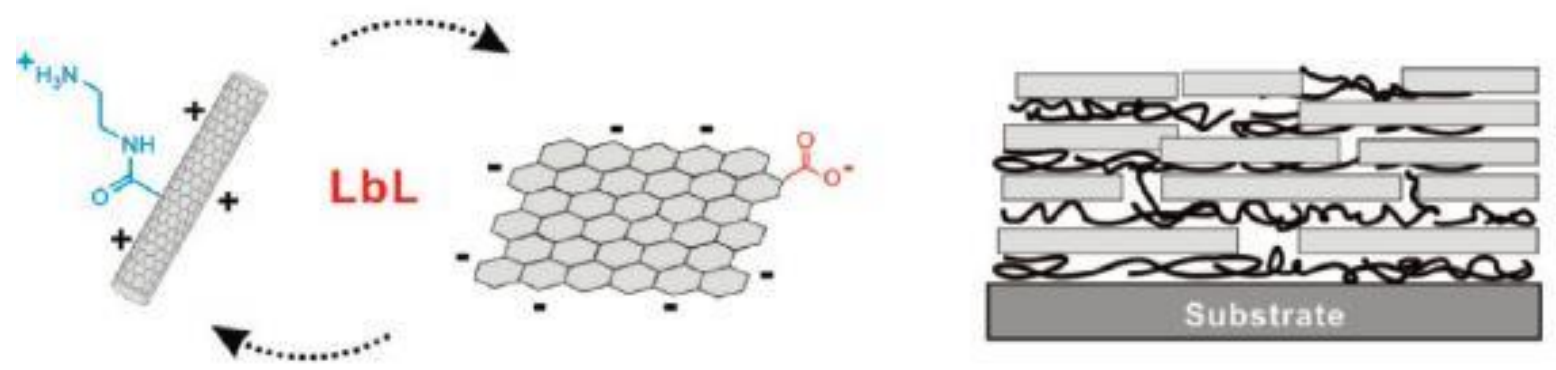

Figure 1 Schematic illustration of positively charged CNTs sandwiched between oppositely charged rGO sheets via electrostatic interaction [16]

This method, which takes maximum advantage of tunable electrical and optical properties results in the production of conducting and transparent thin films with $81 \%$ transparency at $550 \mathrm{~nm}$ and sheet

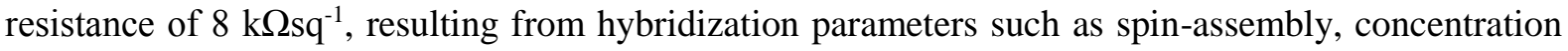
and $\mathrm{pH}$ [16]. The hybridized carbon films were synthesized via self-assembly of the modified 1D CNTs and 2D graphene sheets by means of electrostatic interactions on motley substrates [18]. The films were found to exhibit rectangular cyclic voltammogram (CV) at a scan rate as high as $1 \mathrm{Vs}^{-1}$ and mean specific capacitance of $120 \mathrm{Fg}^{-1}$, being an exquisitely interconnected carbon architectures with well-defined nanoscale pores. These properties could be tailored to applications in supercapacitors [18]. 
In the LBL assembly process, CNTs function to provide mechanical plasticity and electrical conductivity to the hybrid film, while maintaining electrical contact in the graphene nanosheets [17]. Furthermore, the as-prepared hybrid film registered $84 \%$ and $400 \Omega \mathrm{sq}^{-1}$ optical transmittance and sheet resistance respectively, opening up assortment of novel applications in transparent electronics. However, the absence of well-controlled architectures in the resulting 2D nanostructures limits the application landscape of LBL assembly. Another issue that complicates this approach is the sheer difficulty in fabricating carbon-carbon (C-C) covalent bonding between CNTs and graphitic layers in the hybrid. Recent effort is geared towards efficient synthesis of CNT-graphene hybrid that offers enhanced C-C coupling of CNTs and graphene layers. One possibility is to synthesize CNTs on $\mathrm{GO} / \mathrm{rGO}$ exterior via catalyst-decorated CVD mechanism.

\subsection{One step CNT-graphene hybrids}

This fabrication mechanism involves the simultaneous growth of CNTs and graphene in a single CVD step. Here, the growth substrate of graphene such as magnesium oxide ( $\mathrm{MgO})$ [19], is decorated with the catalyst for CNT growth via immersing in a metal salt solution or via thin film evaporation method. The catalyst decorated substrate is then subjected to CVD synthesis by means of a gas sourced from carbon materials towards synchronous growth of CNTs and graphene. The CNTgraphene hybrid has been successfully grown via CVD technique using hydrothermal-prepared $\mathrm{MgO}$, $\mathrm{Fe} / \mathrm{MgO}$ and lamella-like blended catalyst [19]. The $\mathrm{Fe} / \mathrm{MgO}$ and $\mathrm{MgO}$ function as enhancers, catalysing the growth of CNTs and graphene respectively.

Alternatively, copper $(\mathrm{Cu})$ with engineered physical and chemical properties can be utilized as a catalyst for CNTs-graphene synthesis. To this end, one-step growth of CNT-graphene hybrid has been demonstrated using silicon-nanoparticle (Si-NP) decorated $\mathrm{Cu}$ foil [20]. Here, the Si-NP functions as a scaffold upon which $\mathrm{Cu}$ is decorated at high temperature to form nanoparticle catalyst that promote CNT growth. The resulting CNTs with bamboo-shaped architecture was found to uniformly span the entire surface of graphene. In a catalyst-free technique, Yu et al. [21] demonstrate a catalyst-free and chemically fused CNT-graphene hybrid structure grown from CNTs which function as growth substrate for graphene. In this mechanism, methane $\left(\mathrm{CH}_{4}\right)$ and argon (Ar) are respectively employed as carbon gas and carrier gas to subject CNTs to plasma enhanced chemical vapour deposition (PECVD). Consequently, the Ar plasma precipitates defects in the CNTs initiating nucleation sites and snaps $\mathrm{CH}_{4}$ into free carbon, resulting in few-layer graphene morphologies, as illustrated in Figure 2.
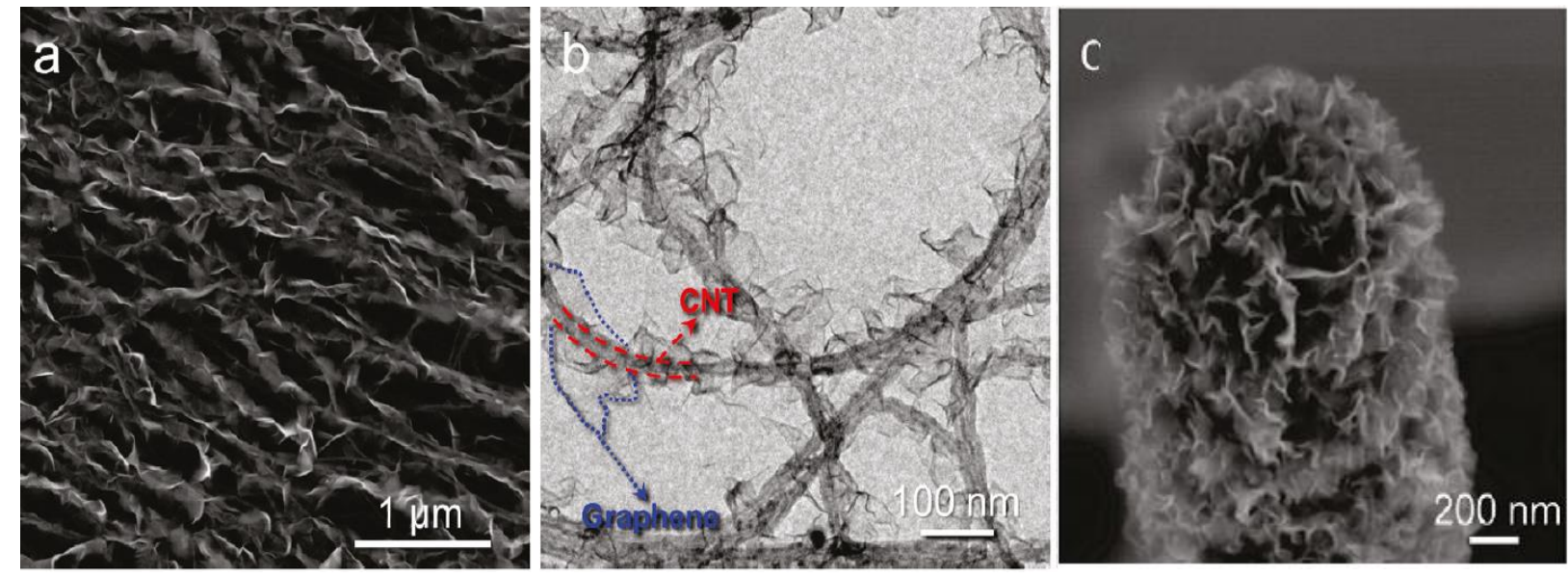

Figure 2 Schematic of few-layer graphene leafy architecture grown on CNT (CNT-FLG) (a) SEM image of CNT-FLG hybrid (b) TEM image of CNT-FLG hybrid (c) A near view of the tip of CNT-FLG hybrid [21]. 
The electrical and thermal conductivities of CNTs have been found to be significantly attenuated in intertwined structures due to disconnected contact of CNT ensembles [22]. This problem can be addressed by growing inverted and vertically-oriented CNTs on graphene layers using one-step method. Yan et al. [23] synthesized graphene directly from porous Ni films by growing controlled length dimensions of vertically oriented CNT forests that arise from the graphene exterior. Similarly, $\mathrm{Du}$ et al. [24] report the growth of vertically oriented CNTs sandwiched between highly ordered thermally expanded pyrolytic graphite (HOPG) utilizing catalyst-sourced pyrolysis. Here, HOPG was acid-treated, causing the acid molecules to clog to the HOPG sheets. The entangled HOPG sheets were then separated via thermal agitation. The disconnected HOPG were decorated with silicon dioxide $\left(\mathrm{SiO}_{2}\right)$ before vertically oriented CNTs were sandwiched between the sheets via thermal pyrolysis of $\mathrm{Fe}$ rich precursor to synthesize to a $3 \mathrm{D}$ pillared structure. 3D pillared structures synthesized from CNTs sandwiched between parallel oriented graphene sheets exhibit superior mechanical properties and out-of-plane electrical transport phenomenon, while retaining in-plane properties of individual materials. In addition, they assume an enhanced surface dimension which can be exploited for certain applications [24].

\subsection{Multi-step CNT-graphene hybrid}

This hybridization method combines CVD processing with solution-based processing. CNTs, graphene or their hybrids can be well grown or synthesized onto a substrate via CVD. Thus, CVD is promising for the synthesis of carbon-based nanoelectronic materials. During CVD processing, gaseous precursors are catalytically converted to solid media at the exterior of catalyst particles. The schematic assembly to grow single wall nanotubes (SWNTs) onto rGO films is shown in Figure 3. In this procedure, GO platelets are deposited in aqueous colloidal suspensions, followed by coating the platelets with nanoparticle based metal catalyst to form graphene films with enlarged surface area. The growth of the CNT is then enhanced via isolating the nanoparticles on motley spin-decorated substrates in the CVD mechanism for CNT-graphene hybridization. CVD enjoys the advantages of applicability to all carbon based devices, high yield and ease of preparation, making it the preferred choice for CNT-graphene hybrid synthesis. For instance, high conductivity CNT matrix decorated graphene films have been prepared via CNT-graphene hybridization. The nucleation phase of this mechanism involves high temperature catalytic etching of imperfections using $\mathrm{Cu}$ resulting in high concentration of carbon atoms contiguous to the CNTs. This initializes the next phase with the production of graphene nuclei which function as promoters. In the enlargement phase, cascaded ensembles of CNTs function as diffusion blockades of carbon adatoms to effectively adjust the morphologies of the growing graphene landscape. Consequently, the CNTs and graphene melds into a continuous film, forming CNT-graphene hybrid [15].

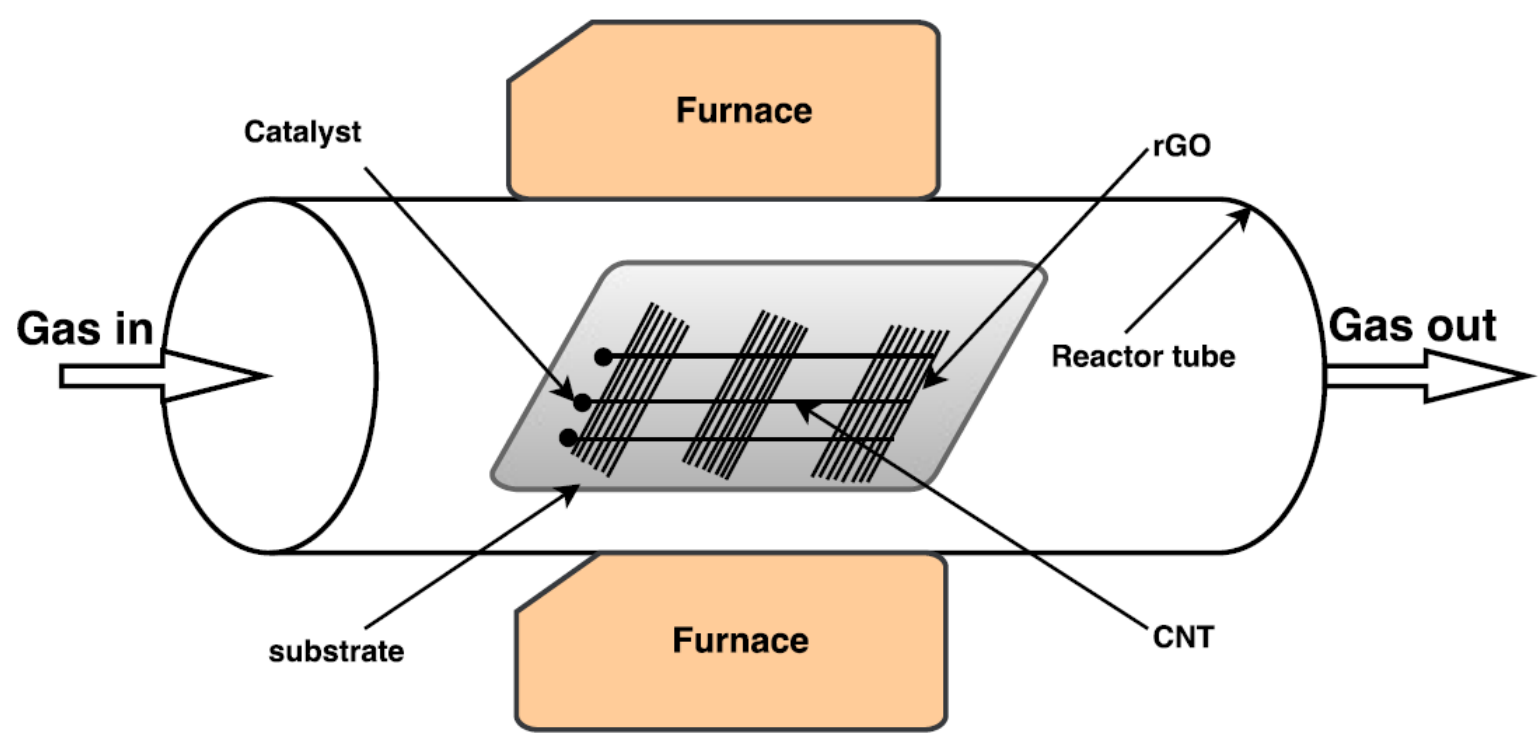




\section{Figure 3 Schematic of CVD procedure for synthesizing SWCNTs on rGO film}

Lin et al. [25] demonstrate the hybridization of CNTs and graphene via $\pi-\pi$ stacking rather than covalent wedding, resulting in excellent planar graphene/ CNT hybridized morphology. The CNTs toughen the graphene via covalent bonding and $\pi-\pi$ stacking loci where the CNTs unzip, forming a seamless unified 2D structure [26]. This unified hybrid was found to exhibit a sheet resistance of $\sim 600 \Omega \mathrm{sg}^{-1}$ and a transmittance of $\sim 95.8 \%$ at $550 \mathrm{~nm}$ reflecting enhanced performance over those of CNT films and stacked CVD two-layer graphene at identical transmittance [26].

\subsection{Dispersion/Physical blending}

The employment of Hummers method in preparing GO enriches it with numerous oxygen-containing functional groups making it readily soluble in water. When suspended in water, CNTs agglomerate and therefore requires surfactants for unvarying dispersion. However, the $\pi-\pi$ interaction of GO with CNTs and its towering dispersibility in water provide efficient dispersion route without need for surfactants. In addition, the restacking of graphene oxide sheet is blocked [27].

The dispersibility of GO can be significantly enhanced via increasing the quantum of oxygencontaining ensemble, although the electrical conductivity of GO is sacrificed as defects are bound to build up in the $\mathrm{sp}^{2}$ network which raises the $\mathrm{sp}^{3}$ content. The diminished electrical conductivity of GO can be reconstructed via deoxygenation or reduction using hydrothermal and chemical techniques [28]. The after and simultaneous reduction of GO during the hybridization of CNTs and graphene (CNT-graphene) architectures yields conductive single-layer of chemically redesigned graphene with uniformly cascaded network of CNTs. Such hybrid has been fabricated via sonication enabled blending of acid modified CNTs with GO and alkaline-based simultaneous deoxygenation [29]. In addition, Tung et al. [30] prepare a similar CNT-graphene hybrid by dispersing partially oxidized CNTs and power forms of GO in anhydrous hydrazine. Their results show a more stable anhydrous hydrazine enabled dispersion of CNT-graphene in aqueous rather than organic solvents (see Figure 4).
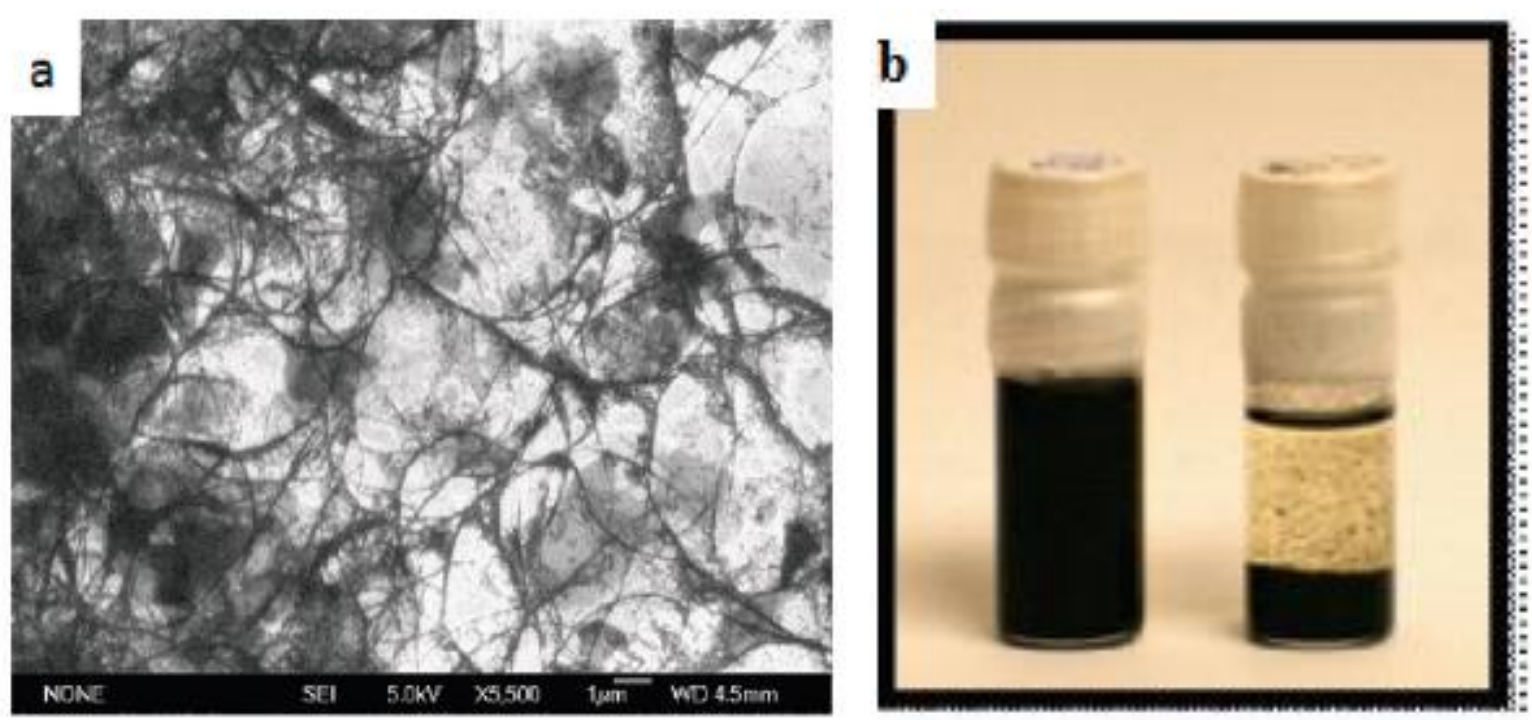

Figure 4 Preparation of CNT-rGO hybrid via dispersion and reduction of blended CNT-GO in anhydrous hydrazine. (a) SEM image of CNT-graphene film, (b) Stable dispersion of CNT-GO in anhydrous hydrazine (left) relative to organic solvent (right) after $12 \mathrm{~h} \mathrm{[30]}$

\subsection{Chemical Vapour deposition (CVD)}

Chemical vapour deposition has remained a key synthesis method for individual CNTs and graphene. CVD can be employed to grow CNTs-graphene hybrid via direct growth methodology which can 
control the hybrid by tuning growth conditions [31-32]. This methodology enjoys the unique advantages of uncomplicated processing and uniformly distributed CNTs on graphene sheets. Yu et al. [21] demonstrate the growth of CNT-graphene hybrid via plasma enhanced CVD (PECVD) using CNTs as substrate for cracking $\mathrm{CH}_{4}$ where imperfections in the CNTs created nucleation loci and $\mathrm{CH}_{4}$ was snapped into carbon to form few-layer graphene sheets. The as-grown few-layer graphene and the host CNTs are chemically unified or intrinsically integrated via the $\mathrm{sp}^{2}$ carbon atoms, yielding a single, all carbon morphology diminished CNT-graphene junctions. Although not shown here, the few-layer graphene was found to span the entire landscape of every single CNT. The tip of the CNT tube was also found to be capped by a large portion of the few-layer graphene corolla despite the uniform diameter of the CNT stem.

Mao et al. [33] report a novel growth technique in which CNTs are directly grown on the surface of crumbled graphene layer to form CNT-graphene hybrid. In the present paradigm, the crumbled graphene layer surface is decorated with permeable CNTs matrix affording the hybrid exceptional hierarchical morphology with potential for novel applications in supercapacitors. The first phase of this mechanism exploits one-pot ultrasonic nebulizer-based technique to produce crumbled graphene ball/ $/ \mathrm{Fe}_{3} \mathrm{O}_{4}$ nanocrystall hybrid. In particular, the $\mathrm{GO}$ suspension with the precursor ions was nebulized to precipitate aerosol droplets that channelled through a tube furnace. The micrometer dimension of the precipitated droplets triggered rapid evaporation of the solvent in the tube furnace, prompting sudden shrinkage of GO, followed by compression of the GO layers into crumbled balls with submicrometer dimension. At the same time, the precursor ions synthesize to $\mathrm{Fe}_{3} \mathrm{O}_{4}$ nanocrystals which get buried on both internal and external exteriors of the crumbled graphene ball via a CVD technique employing $\mathrm{Fe}$ as a catalyst. The CVD synthesis of $\mathrm{C}_{2} \mathrm{H}_{2}$ gas as carbon origin and the reduction of the crumbled graphene ball/ $/ \mathrm{Fe}_{3} \mathrm{O}_{4}$ hybrid structure with diatomic hydrogen $\left(\mathrm{H}_{2}\right)$ characterize this growth phase.

Jiang et al. [34] report a CVD based CNT-graphene synthesis technique in which arrays of CNTs are grown on two sides of graphene, with vertically oriented CNT arrays grown atop surface of graphene (T-CNT) and beneath graphene (B-CNT). Graphene is then sandwiched between the two layers as shown in Figure 5 a. The SEM images of the sandwiched hybrids as viewed from one side at varying magnifications (Fig. $5 \mathrm{~b} \& \mathrm{c}$ ) show an unbending B-CNT with height dimension of about 15 $\mu \mathrm{m}$, consistent with CNTs grown without graphene film atop. This is in contrast to as-grown T-CNT which is visibly curved, with the dash-marked graphene layer delineating the interface between $\mathrm{B}$ CNT and T-CNT (Fig. 5 d). The as-described procedure employs $\mathrm{Al}_{2} \mathrm{O}_{3}$ buffer atop Fe catalyst, and the assembly is deposited onto graphene to grow the tip of B-CNT that lifts the $\mathrm{Al}_{2} \mathrm{O}_{3} / \mathrm{Fe}$ film. While the base-growing CNTs underneath and the tip-growing CNTs atop graphene initiate contacting of CNTs on both sides of graphene, the buffer/catalyst film ensures synchronous growth of B-CNT and T-CNT in the CVD mechanism.

\subsection{Liquid phase methods}

This mechanism combines conventional techniques such as electrochemical, solution chemistry and solvothermal/hydro methods with new-fangled paradigms such as successive ionic layer adsorption and reaction (SILAR) and electrospinning. Yan et al. [35] report the growth and subsequent covalent functionalization of graphene quantum dots (GQDs) at the edges of 1,3,5-trialkyl phenyl via stepwise solution chemistry, resulting in an increase in their solubility. The Phenyl ensembles were bonded to one of the transitional molecules instead of the terminal graphene. Consequently, graphene became enclosed in all three dimensions by the bent adjustable peripheral phenyl chains, thus circumventing agglomeration. The robust affinity of the side chains with solvents overcomes the inter-graphene attraction, causing GQDs to be entropically discontinuous which improves its solubility in common solvents. 
To obtain the in situ $\mathrm{Cu}_{2} \mathrm{~S} / \mathrm{rGO}$ hybrid, several action steps are completed [36]. The first phase involves the exfoliation of GO sheets via sonication, followed by complexing with $\mathrm{Cu}^{+}$via electrostatic association of the positively charged ions with the highly electronegative oxygen moieties in GO. The incorporation of ethanol into the mixture triggered disproportionate reaction of $\mathrm{Cu}^{2}$, aiming at sonolytic reduction with $\mathrm{GO}$ functioning as nucleation locus for $\mathrm{Cu}^{+}$. The $\mathrm{GO}$ was reduced via annealing at $250^{\circ} \mathrm{C}$ following the spin-decoration of $\mathrm{Cu} / \mathrm{GO}$ on a fluoride doped tin oxide (FTO) glass. The material was then dipped in a polysulfide suspension and the $\mathrm{Cu}$ on rGO transformed to $\mathrm{Cu}_{2} \mathrm{~S}$. The SEM image of $\mathrm{Cu}_{2} \mathrm{~S} / \mathrm{rGO}$ complex is shown in Figure 6.

(a)
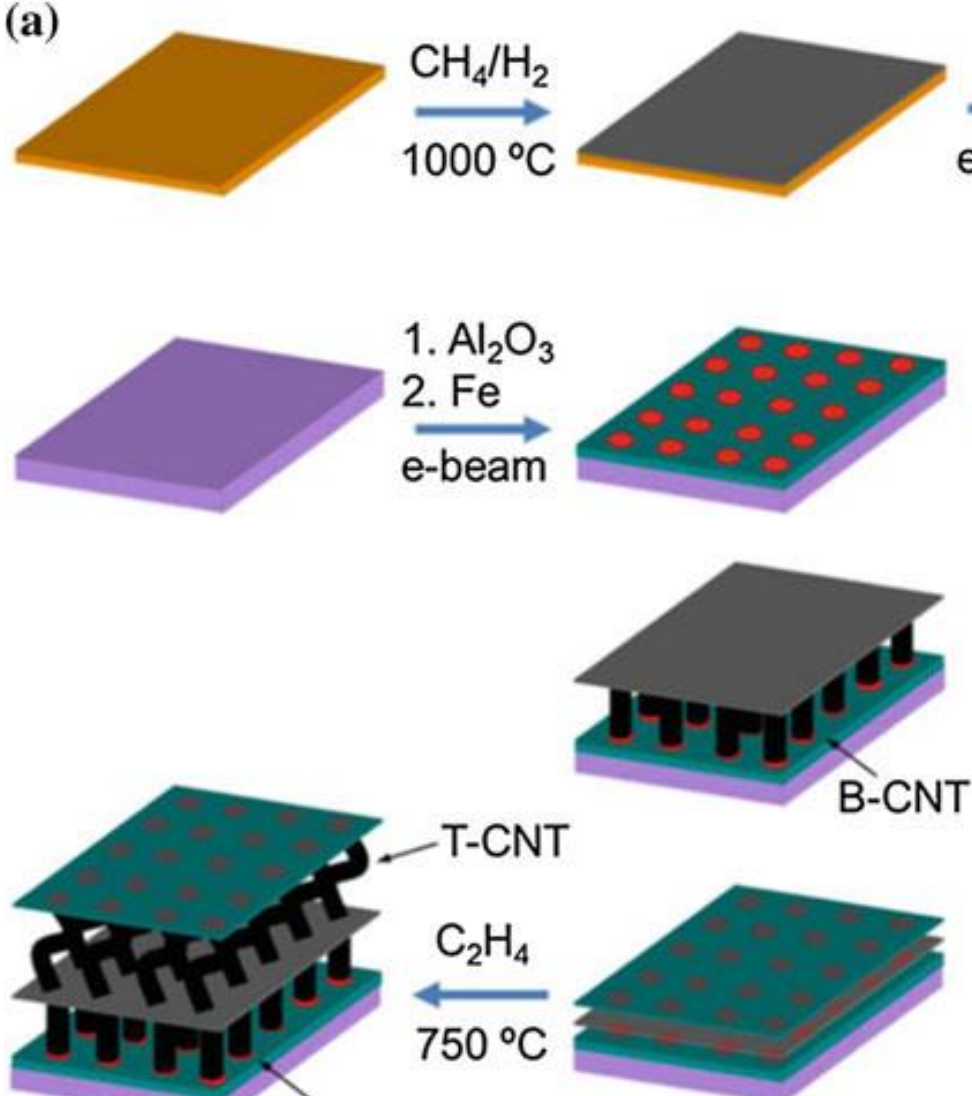

\section{B-CNT}
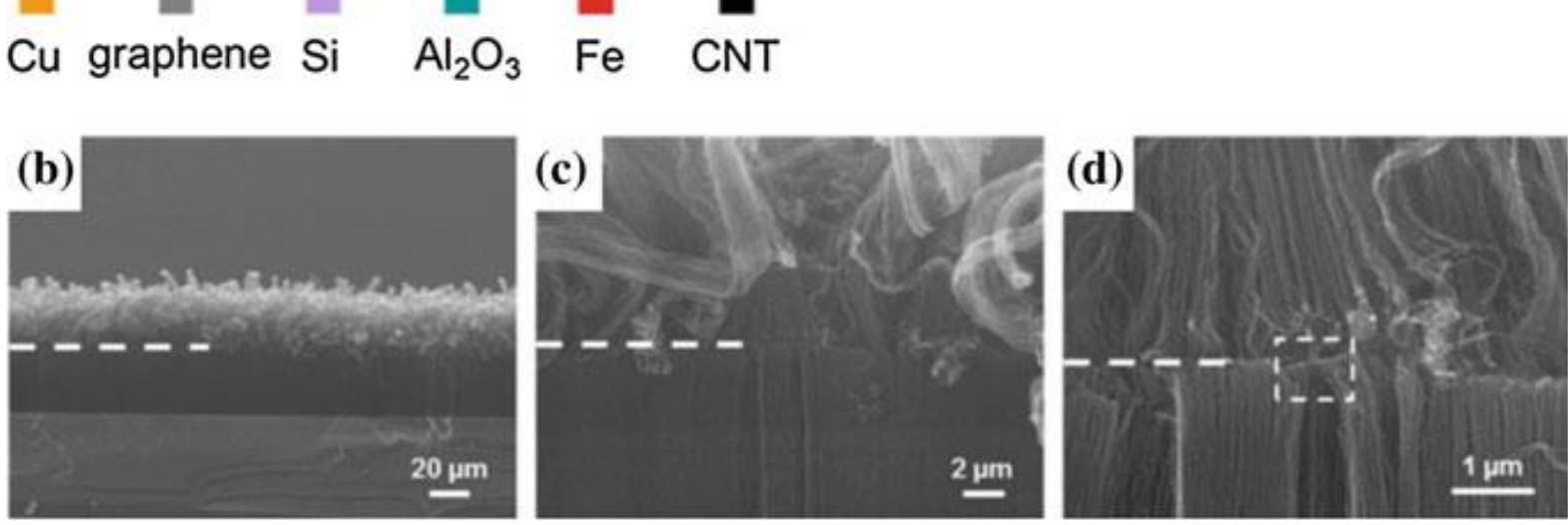
Figure 5 (a) Schematic of synthesis of graphene sandwiched between B-CNT and T-CNT hybrids. (b) CNTs grown underneath graphene to lift up graphene film, or CNTs grown both c) underneath and d) atop of graphene film [34].

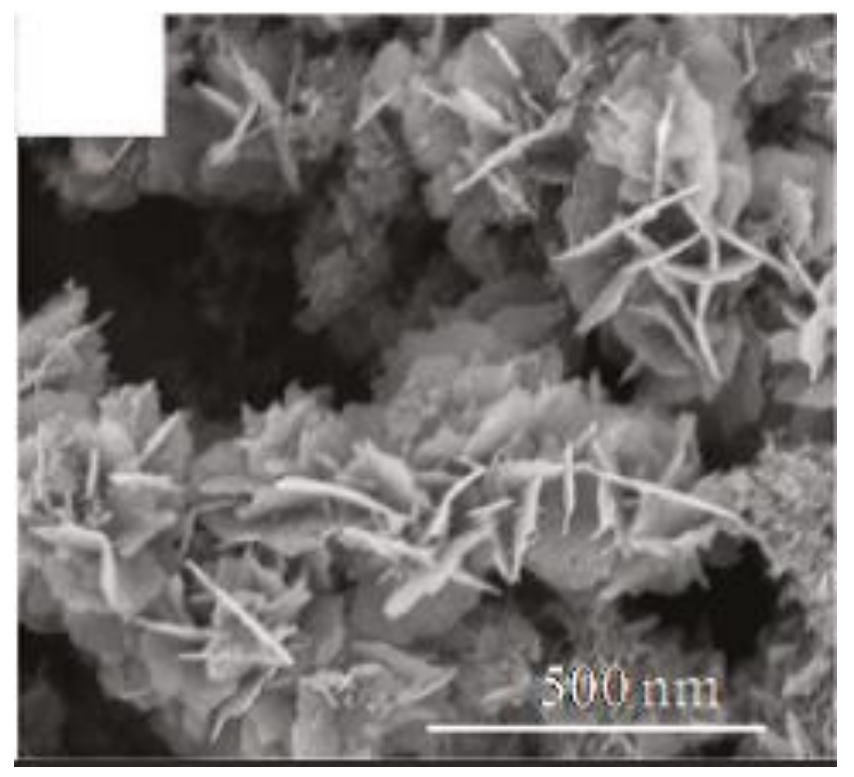

\section{Figure $6 \mathrm{SEM}$ image of $\mathrm{Cu}_{2} \mathrm{~S} / \mathrm{rGO}$ complex grown via solution chemistry [36]}

Solvothermal and hydrothermal techniques rather than gas phase methods are the preferred choice when employing polymeric substrates for pliable products, as temperature dependency is significantly diminished. Whether water or organic solvent is utilized depends on the method employed. The zinc oxide $(\mathrm{ZnO})$ in the hydrothermal technique showed no preferential growth in the domain boundaries and step edges for the reason the authors ascribe to the nucleation and growth of the particles in the solution rather than on the surface, making nucleation less dominated by surface state in contrast to the gas phase. Similarly, using CVD or exfoliated graphene yields similar results in terms of concentration, temperature and $\mathrm{pH}$ effects [37]. However, when the precursor is an organic molecule, organic solvents are preferred. For instance, when employed as precursors, the molecules of titanium isopropoxide are grafted unto graphene via chemisorption during growth of titanium oxide $\left(\mathrm{TiO}_{2}\right)$. $\mathrm{TiO}_{2}$ based nanoparticles synthesized via solvothermal technique showed progressive increase in dimension with every increase in growth temperature [38]. $\mathrm{TiO}_{2}$ have also been grown via systematic blending of solvo/hydrothermal techniques [39]. Here, the metallic Ti was first intercalated with GO via blending a suspension of $\mathrm{GO}$ and a solution of titanium tetraisopropoxide followed by refluxing at a temperature of $65^{\circ} \mathrm{C}$. The resulting mixture (Ti/GO) was blended with $10 \mathrm{M}$ concentration sodium hydroxide $(\mathrm{NaOH})$ and then subjected to heat treatment at a temperature of $150^{\circ} \mathrm{C}$ for $24 \mathrm{~h}$ timescale. The synthesized $1 \mathrm{D} \mathrm{TiO}_{2}$ was found to be deposited and oriented in $2 \mathrm{D}$ fashion along the exterior of the carbon nanosheets without aggregating.

SILAR is mainly employed to synthesize quantum dots on various substrates. This method has been used in combination with LBL assembly to synthesize QD (CdS), stacked triple-composite with titania nanosheets (TNS) and rGO. The material was then subjected to SILAR cycle, a sequential immersion in solutions of $\mathrm{H}_{2} \mathrm{O}, \mathrm{Cd}\left(\mathrm{NO}_{3}\right)_{2}$ and $\mathrm{Na}_{2} \mathrm{~S}$ following one cycle of LBL stacking of $\mathrm{GO}$ and TNS, which enriches CdS with ions. The stacking phase is repeated multiple times. Finally, GO was reduced with hydrazine evaporation and annealed at a temperature of $400^{\circ} \mathrm{C}$ [40-43].

\subsection{Gas phase methods}


These include atomic layer deposition (ALD), physical evaporation deposition (PVD), metal-organic vapour phase epitaxy (MOVPE) and CVD for the growth of graphene/SNM hybrid. Figure 7 shows the schematic assembly of the gas phase synthesis system consisting of impactor, spark generator, neutralizer, electrostatic precipitator (ESP), differential mobility analyser (DMA) and condensation particle counter (CPC). CVD is popular for the growth of zinc oxide $(\mathrm{ZnO})$ on graphene, given its well established moderate boiling and melting point temperatures [44]. This method is characterised by varying range of morphologies such as nanometric walls, ribbons, particles, tetrapods and rods, depending on the employed metallic catalyst and graphene pre-treatment methodology. For instance, while randomly oriented nanoribbons are produced in the absence of any catalyst, aligned nanorods are produced when graphene surface is treated with Au catalyst. A mechanism that clogs massive quantum of $\mathrm{Zn}$ on graphene surface with less sticking effect, and therefore randomly orients the nanoribbons is proposed. MOVPE has also been employed to grow $\mathrm{ZnO}$ on graphene by flowing organic $\mathrm{Zn}$ precursor and oxygen in a gas phase reactor. The gas molecules disintegrated when contacted with graphene surface, causing $\mathrm{ZnO}$ to be adsorbed on the surface. This mechanism yields extremely crystalline materials that are free from defects.

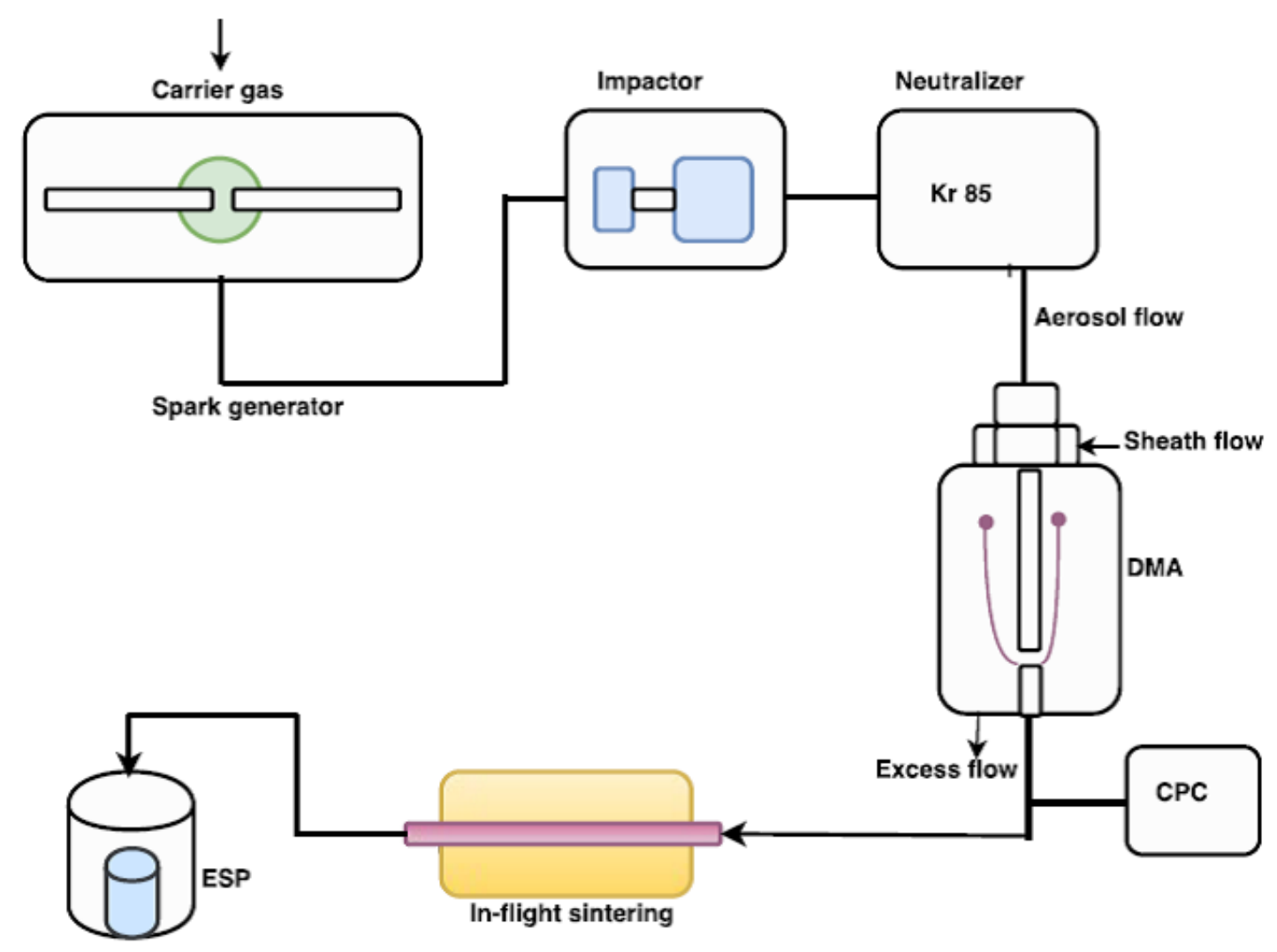

Figure 7. Schematic diagram of a gas phase synthesis system

For its part, titania cannot be synthesized via MOVPE due its high transition temperature. This means that other attractive synthesis methods such as e-beam evaporation are explored. For instance, $\mathrm{TiO}_{2}$ in rutile or anatase state with less than $5 \mathrm{~nm}$ scale dimensionality has been successfully grown on graphene via direct e-beam evaporation [45]. Similarly, $\mathrm{TiO}_{2}$ has been prepared by means of ALD via solid-gas synthesis path characterized by two successive cyclic self-limiting half-reactions resulting in a LBL growth mode. Here, the precursors make direct reaction in the substrate without decaying in reaction, in contrast to CVD. Meng et al. [46] demonstrate graphene nanosheet decorated with $\mathrm{TiO}_{2}$ via $\mathrm{ALD}$ accomplished at a temperature range of 150 to $250^{\circ} \mathrm{C}$. 


\section{APPLICATIONS OF CNT-GRAPHENE HYBRID}

Carbon nanotube-graphene hybrid holds great promise for a variety of applications [47-50], not possible with individual materials. In this section, we outline the latest applications of this wonder CNT-graphene hybrid structure.

\subsection{Sensors}

The increasing number of diabetic patients worldwide has ignited research interest in clinical biosensing and glucose biosensors dominate in this aspect. Biosensor detect enzymes mainly via amperometry, although non-enzymatic glucose detection has recently been reported. For instance, GO electrode [51] and Pt nanoflowers coated on in situ CNT-graphene hybrid [52] have been demonstrated for non-enzymatic sensing of blood glucose.

The as-described enzymatic glucose biosensors utilize glucose oxidase (GOx) owing to its stability and specificity to glucose. GOx catalyses the oxidation of oxygen enriched glucose to yield hydrogen peroxide $\left(\mathrm{H}_{2} \mathrm{O}_{2}\right)$ and gluconolactone. The chemistry of this mechanism can be found in the following literature [53]. The enzyme flavin adenine nucleotide (FAD) is at the active centre of the redox reaction. The $\mathrm{H}_{2} \mathrm{O}_{2}$ generated at the electrode was electrochemically detected in first designed glucose biosensors due to enzymatic action, although $\mathrm{H}_{2} \mathrm{O}_{2}$ production is oxygen dependent, requiring extreme detection potential which naturally interferes with other redox composites. In second generation biosensors, however, oxygen dependency is eliminated thanks to redox mediators. These mediators are in constant motion, and can be wired to an enzyme transfer electrons to the electrode or diffuse unimpeded to FAD or the other way round resulting in the generation of amperometric signal. Glucose biosensing in third generation biosensors can be achieved at a lower potential without the need for redox mediators via direct electron transfer (DET) from redox centre to the electrode.

Direct electron transfer is difficult to attain with GOx enzyme bare electrodes as FAD is deeply embedded in the formation. CNT-graphene hybridized structure yields highly conductive and methodical matrix for fast electron transfer kinetics and enzyme immobilization towards mediator free realization of DET for GOx, with positive implications in glucose sensing. Although the exact mechanism of DET is not yet known, the superior electrochemical properties of the contiguous highly conductive graphene and CNT-graphene hybrid presents interesting clues. The existence of FAD redox tops in cyclic voltammetry with traditional potential approximating GOx standard electrode potential is a significant marker of GOx DET scheme [54]. The glucose is then detected via measuring the rise in the peak current of positively charged FAD in response to glucose oxidation or on the decline in peak current of the negatively charged FAD owing to oxygen utilization/reduction. Glucose detection utilizing oxygen can well be realized at low potential, being an instance of mediator-free sensing, and therefore atypical of third generation sensors.

CNT-graphene hybrid affords increased surface area for enzyme immobilization and generates 3D conductive matrix for effective electron transfer to contiguous enzyme molecules. During the oxidation mechanism, GOx is immobilized on the CNT-graphene electrode and DET from redox enzyme centre of action as shown in schematic of Figure 8. CNT-graphene hybrid assembled via physical means using CNTs and GO is shown to achieve DET for GOx via cathode based oxygenutilizing glucose biosensing [55]. Furthermore, the electrochemically active area was increased for CNT-graphene hybrid modified with $\mathrm{ZnO}$ nanoparticles, which raises the possibility of improved enzyme immobilization and fast electron transfer scheme [56]. This procedure employs differential pulse voltammetry to detect glucose taking advantage of oxygen depletion in the system.

\subsection{Material science}

Recently, Ahmad et al. [57] report promising applications of CNT-graphene reinforced ceramics in biomedical, aerospace, automotive and photonic technologies resulting from enhanced toughness and 
other beneficial properties of the starting hybrid material. In addition to the amplified performance of $\mathrm{Al}_{2} \mathrm{O}_{3}$, the substantially enhanced capability of the hybrids to withstand wear could be attractive for a number of sliding and wear applications in automotive technology like piston rings, cylinder line and valve seat [58]. Additionally, the CNT-impregnated $\mathrm{SiC}, \mathrm{BaTiO}_{3}$ and $\mathrm{Si}_{3} \mathrm{~N}_{4}$ systems were found to assume properties suitable for structural applications. The chemical and thermally stable ceramic hybrids could adjust their extreme thermal conductivity, making them attractive choice for high temperature applications. Furthermore, CNTs/graphene hybrid has the potential to transform ceramics into functional materials for automotive and aerospace applications. In addition, the out-of-plane electrical properties of CNT-graphene hybrid make $\mathrm{Al}_{2} \mathrm{O}_{3}$ ceramic assume properties suitable for certain specialized applications [59-60].

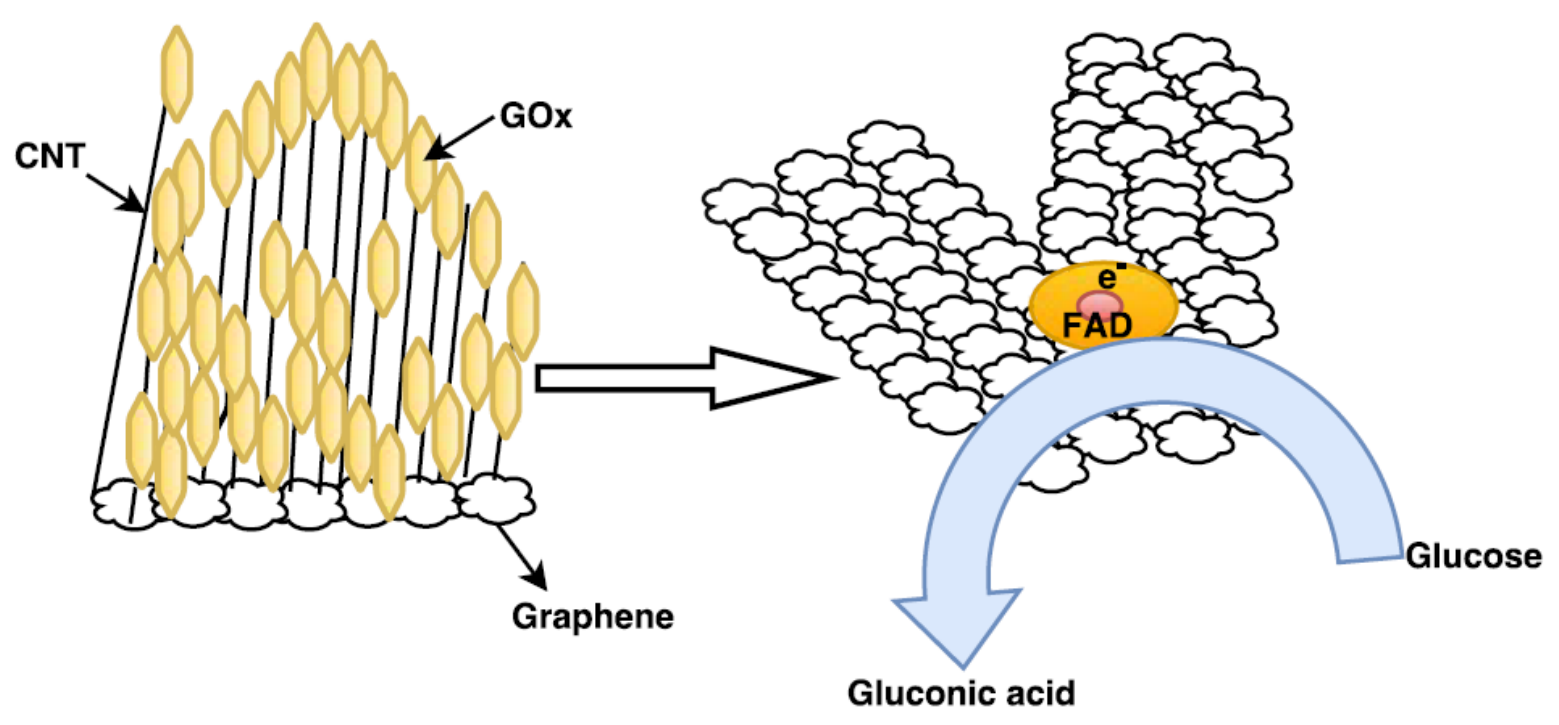

Figure 8 Schematic illustration of electron transfer from redox centre of immobilized GOx molecule on CNT-graphene and biosensing oxidation of glucose.

\subsection{Energy/supercapacitors}

Carbon nanotube-graphene hybrid structures are considered highly attractive for supercapacitor applications due to their rich electrical/thermal conductivity, mechanical stability, plasticity, electrochemical solidity and enhanced surface area [61]. Supercapacitors possess enhanced capacitance than conventional capacitors. Yan et al. [62] fabricate $\mathrm{MnPO}_{4} \cdot \mathrm{H}_{2} \mathrm{O}$ nanowire-GO hybrid material with decorated GO which exhibited high specific capacitance of $287.9 \mathrm{Fg}^{-1}$ at $0.625 \mathrm{Ag}^{-1}$ and specific power capability of $1.5 \times 10^{5} \mathrm{Wkg}^{-1}$ at $2.271 \mathrm{Whkg}^{-1}$, presenting novel opportunities in supercapacitor applications. Xue et al. [63] demonstrate a novel one-step CVD technique that directly grows unfilled fibers formed from radially oriented CNTs (ROCNTs) arrays sandwiched by cylindrical graphene sheets with covalently glued seamless pristine $\mathrm{C}-\mathrm{C}$ nodal intersections between ROCNTs and graphene. These novel CNT-graphene hybrids are instrumental to the rational design of micro -nano/mesoporous architectures with enhanced surface area and diminished interfacial electrical resistances. These features make ROCNTs-graphene hybrid architectures ideal electrodes for energy efficient supercapacitors.

Carbon nanotubes-graphene hybrid architecture exhibits rich direction-dependent electrical and thermal transport properties with diminished out-of-plane conductivities owing to the presence of strong covalent interface in the carbon plane and weakened van der Waals forces in the transverse orientation between the layers. 3D pillared VOCNT-graphene hybrid architecture doped with lithium (Li) cations is shown to efficiently store hydrogen consistent with computer modelling [64]. Moreso, the transport properties of 3D pillared VOCNT-graphene architecture is found to be theoretically 
governed by CNT-pillared dimension and minimum interpillar distance [65]. Recent advances in the fabrication of single layer of VOCNTs on graphene substrate or randomly oriented CNT-graphene sandwiches have yielded positive results [66-67], although some challenges remain.

Table 1 summary of SSC performance using CNT-graphene/graphene and other related hybrids

\begin{tabular}{|c|c|c|c|c|c|}
\hline $\begin{array}{l}\text { CNT-graphene/graphene/ } \\
\text { other related electrodes }\end{array}$ & $\mathrm{J}_{\mathrm{sc}}\left(\mathrm{mA} / \mathrm{cm}^{2}\right)$ & $\mathrm{V}_{\mathrm{oc}}(\mathrm{V})$ & $\mathrm{FF}(\%)$ & $\mathrm{n}(\%)$ & Ref. \\
\hline CE: MWCNT-rGO/FTO & 16.05 & 0.75 & 62.7 & 7.55 & [68] \\
\hline CE: Pt NPs/graphene nanosheets/FTO & 18.26 & 0.72 & 65 & 8.54 & [69] \\
\hline CE: $\mathrm{Cu}_{2} \mathrm{~S}$-rGO-PVA binder/FTO & 18.4 & 0.52 & 46 & 4.40 & [36] \\
\hline PA: N3/ $\mathrm{TiO}_{2}-\mathrm{rGO}$ & 16.29 & 0.69 & NA & 6.97 & {$[70]$} \\
\hline CE: rGO-CNT/FTO & 15.25 & 0.68 & 51.05 & 5.29 & {$[10]$} \\
\hline PA:N719/TiO ${ }_{2}$-graphene nanofiber/FTO & 16.2 & 0.71 & 66 & 7.6 & [71] \\
\hline PA: MWCNT-rGO-TiO $/$ FTO & 11.27 & 0.78 & 70 & 6.11 & [72] \\
\hline CE: graphene nanoplatelets-Pt NPs/FTO & 14.31 & 0.735 & 61.9 & 6.51 & {$[73]$} \\
\hline PA: ZnO-graphene QD/Cs ${ }_{2} \mathrm{CO}_{3} / \mathrm{AI}$ & 0.196 & 0.99 & 24 & 2.23 & [74] \\
\hline CE: VOCNT-graphene paper & 14.24 & 0.68 & 62.4 & 6.05 & {$[75]$} \\
\hline CE: SWCNT-rGO/FTO & 12.81 & 0.9 & 76 & 8.37 & {$[76]$} \\
\hline PA: (TNS)-rGO-CdS QD) ${ }_{10} / \mathrm{FTO}$ & 0.92 & 1 & 41 & 0.38 & [77] \\
\hline PA: Graphene QD/TiO $/$ FTO & 0.2 & 0.48 & 58 & NA & [35] \\
\hline CE: $\mathrm{CulnS}_{2}$-rGO/FTO & 16.63 & 0.74 & 51 & 6.18 & [78] \\
\hline
\end{tabular}

$\mathrm{CE}$, Counter electrode; PA, photoanode; $\mathrm{J}_{\mathrm{sc}}$, Short circuit current density; $\mathrm{V}_{\mathrm{oc}}$, open circuit voltage; FF, Filling factor; n, energy conversion efficiency

CNT-graphene hybrid architectures have recently been suggested as a promising counter electrode material in stretchable supercapacitors (SSCs), and as part of photoanode and electrolyte as well [79]. When incorporated in a counter electrode, CNT-graphene hybrid can bridge the gaps between flakes while providing improved electrical conductivity to the assembly. The improved electrical and catalytic properties are capable to provide cell performance that slightly exceeds one obtained from individual CNTs and graphene. Dembele et al. [80] obtain similar results via incorporating CNTs with nanoparticles of $\mathrm{TiO}_{2}$ instead of graphene, suggesting that performance is influenced only when CNTs are chemically hybridized with graphene or at least with any metallic nanoparticle, in this case $\mathrm{TiO}_{2}$ nanoparticle. Table 1 summarizes the performance of CNT-graphene/graphene and other related hybrids in SSCs. For their part, Li et al. [75] demonstrate VOCNT-graphene hybrid for SSC counter electrode reaching $83 \%$ cell efficiency of a Pt film electrode and enhanced efficiency to tangled CNT owing to diminished transportation route. The advantages of hybridizing, and subsequent integration of CNTs and graphene in photoanodes, where the adsorption of CNTs is shown to increase the extent of dye adsorption while diminishing recombination and aggregation at the intersection of graphene sheets, have been highlighted [72]. Meanwhile, the chemical combination of CNTs and graphene is found to remarkably enhance conductivity, mainly via promoting carrier charge transport in the hybrid [81]. Similarly, Kaner et al. [30] demonstrated increased film conductivity for thionyl chloride $\left(\mathrm{SOCl}_{2}\right)$ vapour-treated hybridization of CNTs and chemically converted graphene films.

\section{CONCLUSION AND FUTURE PERSPECTIVES}

A wide variety of growth methodologies have been employed to assemble CNT-graphene hybrid by melding 1D CNTs and 2D graphene into a unified novel 2D or 3D sp²-hybridized carbon architectures via intermolecular induced intersections between the individual CNTs and graphene sheets. CNTs- 
graphene hybrid holds great promise as a material for novel research on planar hybrid architectures of the future. However, the fabrication of controllable CNTs-graphene hybrid exploiting one-pot mechanism is still challenging due to scalability concerns. Here, the possible applications of CNTgraphene hybrid architectures are presented. In most cases, CNT-graphene exhibited superior performances than individual pristine CNTs or graphene, reflecting their potentials for various practical and research applications. Whether as an electrode in mediator-free glucose biosensors, charge collector platform, electron transfer aid or a photoactive material, CNT-graphene hybrid's use and research awareness has been steadily expanding and impacting modern day carbon based electronics. The hybridization of pristine CNTs and graphene can be performed via countless methodologies that continue to be discovered. When designing CNT-graphene hybrid architecture, great attention must be focused on optimizing the intrinsic properties of the components simultaneously with mechanisms of electronic coupling and interface alignments, some of which still remain a mystery. As we have selectively reviewed new perspectives on CNT-graphene hybrid design, with focus on sensing and energy applications, it is easy to notice that this trend of employing CNT-graphene hybrid with their multimodalities and multifunctionalities will continue to expand in fields of chemical sensing, solar cells, medical diagnostics, flexible electronics and many other transduction technologies.

\section{ACKNOWLEDGMENT}

The authors wish to thank Universiti Malaysia Pahang (UMP) for their financial support through research grant scheme of the Ministry of Higher Education (MOHE), Malaysia. The authors also acknowledge the Research \& Innovation Department (RID) of UMP for providing excellent research environment to complete this work.

\section{REFERENCES}

[1] Higgins D., Zamani P., \& Yu A. "The application of graphene and its composites in oxygen reduction electrocatalysis: a perspective and review of recent progress". Energy Environ. Sci. 9, 357-390. Doi: 10.1039/C5EE02474A, 2016.

[2] Halder A., Zhang M., \& Chi Q. "Electrocatalytic Applications of Graphene-Metal Oxide Nanohybrid Materials. In Advanced catalytic Materials: Photocatalysis and other Current Trends'. Chapter 14, 379-414. In Tech Open Access Publishers. Doi: 10.5772/61808, 2016.

[3] Georgakilas V., Tiwari J. N., Kemp K. C., Perman J. A., Bourlinos A. B., Kim K. S., \& Zboril R. "Noncovalent Functionalization of Graphene and Graphene Oxide for Energy Materials, Biosensing, Catalytic, and Biomedical Applications'. Chem. Rev. 116(9) 54645519, 2016.

[4] Zhang X., Hou L., Ciesielski A., \& Samori P. “'2D Materials Beyond Graphene for HighPerformance Energy Storage Applications’’. Adv. Energy Mater. 1600671, 2016.

[5] Hazra S. K., Basu S. "Graphene-Oxide Nano Composites for Chemical Sensor Applications', C 2, 12. Doi: 10.3390/c2020012, 2016.

[6] Anguita J. V., Ahmad M., Haq S., Allam J., Silva S. R. P. "Ultra-broadband light trapping using nanotextured decoupled graphene multilayers". Sc. Adv. 2(2) e1501238.Doi10.1126/sciadv.1501238, 2016. 
[7] Dong X., Wang X., Wang L., Song H., Zhang H., Huang W., \& Chen, P. "3D Graphene foam as a monolithic and macroporous carbon electrode for electrochemical sensing". ACS Appl. Mater. Interfaces 4(6) 3129-3133, 2012.

[8] Prasad K. P., Chen Y., \& Chen P. "Three-Dimensional Graphene-Carbon Nanotube Hybrid for High-Performance Enzymatic Biofuels Cells', ACS Appl. Mater. Interfaces 6(5) 3387-3393. Doi: 10.1021/am405432b, 2014.

[9] Shi W., Chen J., Yang Q., Wang S., \& Xiong C. "Novel Three-Dimensional Carbon Nanotube-Graphene Architecture with Abundant Chambers and its Applications in LithiumSilicon Batteries". J. Phys. Chem. C 2016, 120, 13807-13814. Doi:10.1021/acs.jpcc.6b03864, 2016.

[10] Ma J., Zhou L., Li C., Yang J., Meng T., Zhou H., Yang M., Yu F., \& Chen J. "Surfactant-free synthesis of graphene-functionalized carbon nanotube film as a catalytic counter electrode in dye-sensitized solar cells'.Journal of Power Sources 247, 999-1004. Doi:10.1016/jpowsour.2013.08.145, 2014.

[11] Aravind S. J., Eswaraiah V., \& Ramaprabhu S. "Facile synthesis of one dimensional graphene wrapped carbon nanotube composites by chemical vapour deposition". J. Mater. Chem. 1-4. Doi:10.1039/c1jm12731d, 2011.

[12] lijimma S. "Helical microtubules of graphitic carbon". Nature 354(63430) 56-58, 1991.

[13] Fujisawa K., Kim H. J., Go S. H., Muramatsu H., Hayashi T., Endo M., Hirschmann T. Ch., Dresselhaus M. S., Kim Y. A., \& Araujo P. T. "A review of Double-Walled and TripleWalled Carbon Nanotube Synthesis and Applications". Appl. Sci.6, 109. Doi:10.3390/app6040109, 2016.

[14] ljeomah G., Samsuri F., Zawawi M. A. Md, \& Obite F. "Recent Advances in Chemical Functionalization of Graphene and sensing Applications". International Journal of Biomedical Nanoscience and Nanotechnology [in press], 2016.

[15] Fan W., Zhang L., \& Liu T. "Graphene-Carbon Nanotube Hybrids for Energy and Environmental Applications". Springer Briefs in Green Chemistry for sustainability, Chap. 2. Doi:10.1007/978-981-10-2803-8-2, 2017.

[16] Hong T.-K., Lee D. W., Choi H. J., Shin H. S., \& Kim B.-Su. "Transparent, Flexible Conducting Hybrid Multilayer Thin Films of Multiwalled Carbon Nanotubes with Graphene Nanosheets". ACS Nano 4(7) 3861-3868, 2010.

[17] Zheng Q., Zhang B., Lin X., Shen X., Yousefi N., Hunag Z-D., Li Z., \& Kim J-K. "Highly transparent and conducting ultralarge graphene oxide/single-walled carbon nanotube hybrid films produced by Langmuir-Blodgett assembly'. J. Mater. Chem. 22(48) 2507225082, 2012.

[18] Yu D., Dai L. "Self-Assembled Graphene/Carbon Nanotube Hybrid Films for Supercapacitors'”. J. Phys. Chem. Lett. 1, 467-470, 2010.

[19] Zhu X., Ning G., Fan Z., \& Wei F. 'OOne-step synthesis of graphene-carbon nanotube hybrid decorated by magnetic nanoparticles'. Carbon 50(8) 2764-2771, 2012. 
INTERNATIONAL JOURNAL OF ENGINEERING TECHNOLOGY AND SCIENCES (IJETS) Vol.7 (1) June 2017 DOI: http://dx.doi.org/10.15282/ijets.7.2017.1.10.1072

[20] Lin C-C., \& Lin Y-W. "Synthesis of Carbon Nanotube/Graphene Composites by OneStep Chemical Vapor Deposition for Electrodes of Electrochemical Capacitors'. Journal of Nanomaterials 16(240) 1-8. Doi:10.1155/2015/741928, 2015.

[21] Yu K., Lu G., Bo Z., Mao S., \& Chen J. “'Carbon Nanotube with Chemically Bonded Graphene leaves for Electronic and Optoelectronic Applications', J. Phys. Chem. Lett. 2(13) 1556-1562, 2011.

[22] Wang D., Song P., Liu C., Wu W., \& Fan S. "Highly oriented carbon nanotube papers made of aligned carbon nanotubes". Nanotechnology 19, 075609. Doi:10.1088/09574484/19/7/075609, 2008.

[23] Yan Z., Ma L., Zhu Y., Lahiri I., Hahm M. G., Liu Z., Yang S., Xiang C., Lu W., Peng Z., Sun Z., Kittrel C., Lou J., Choi W., Ajayan P. M., \& Tour J. M., "Three-Dimensional MetalGraphene-Nanotube Multifunctional Hybrid Materials". ACS Nano 7(1) 58-64, 2013.

[24] Du F., Yu D., Dai L., Ganguli S., Varshney V., \& Roy A. K. "Preparation of tunable 3D pillared carbon nanotube-graphene networks for high-performance capacitance". Chem. Mater. 23, 4810-4816. Doi:10.1021/cm2021214, 2011.

[25] Lin Z., Gui X., Gan Q., Chen W., Cheng X., Liu M., Zhu Y., Yang Y., Cao A., \& Tang Z. "InSitu Welding Carbon Nanotubes into a Porous Solid with Super-High Compressive Strength and Fatigue Resistance". Scientific Reports 5:11336. Doi:10.1038/rep11336, 2015.

[26] Li X., Zhu Y., Cai W., Borysiak M., Han B., Chen D., Piner R. D., Colombo L., \& Ruoff R. S. "Transfer of large-area graphene films for high performance transparent conductive electrodes". Nano Lett. 9(12) 4359-4363. Doi:10.1021/n1902623y, 2009.

[27] Qiu L., Yang X., Gou X., Yang W., Ma Z.-F., Wallace G. G., \& Li D. “Dispersing Carbon Nanotubes with Graphene Oxide in Water and Synergistic Effects between Graphene Derivatives". Chemistry 16, 10653-10658. Doi: 10.1002/chem.201001771, 2010.

[28] Pei S., Zhao J., Du J., Ren W., \& Cheng H.-M. "Direct reduction of graphene oxide films into highly conductive and flexible graphene films by hydrohalic acids". Carbon 48, 4466-4474. Doi:10.1016/j.carbon.2010.08.006, 2010.

[29] Chen J., Zheng X., Miao F., Zhang J., Cui X., \& Zheng W. "Engineering graphene/carbon nanotube hybrid for direct electron transfer of glucose oxidase and glucose biosensor". J. Appl. Electrochem. 42, 875-881. Doi:10.1007/s10800-012-0461-x, 2012.

[30] Tung V. C., Chen L.-M., Allen M. J., Wassei J. K., Nelson K., Kaner R. B., \& Yang Y. “LowTemperature Solution Processing of Graphene-Carbon Nanotube Hybrid Materials for Highperformance Transparent Conductors". Nano Lett. 9(5) 1949-1955, 2009.

[31] Yang Y-Y., Zhao Y-F., Xiao Q. Q., Zhang Y-X., Jing L., Yan Y-M., \& Sun K-N. "Controllable Growth of CNTs on Graphene as High-Performance Electrode Materials for Supercapacitors". ACS Appl. Mater. Interfaces 6(11) 8497-8504. Doi:10.1021/am501362g, 2014.

[32] Kumar K., Kim Y-S., Li X., Ding J., Fisher F. T., \& Yang E-H. "Chemical Vapour Deposition of Carbon Nanotubes on Monolayer Graphene Substrates: Reduced Etching via Suppressed Catalytic Hydrogenation Using $\mathrm{C}_{2} \mathrm{H}_{4}{ }^{\prime \prime}$. Chem. Mater. 25(19) 3874-3879. Doi:10.1021/cm402052z, 2013. 
INTERNATIONAL JOURNAL OF ENGINEERING TECHNOLOGY AND SCIENCES (IJETS) Vol.7 (1) June 2017 DOI: http://dx.doi.org/10.15282/ijets.7.2017.1.10.1072

[33] Mao S., Wen Z., Bo Z., Chang J., Huang X., \& Chen J. "Hierarchical Nanohybrids with Porous CNTNetworks Decorated Crumpled Graphene Balls for Supercapacitors". ACS Appl. Mater. Interfaces 6(12) 9881-9889. Doi:10.1021/am502604u, 2014.

[34] Jiang J., Li Y., Gao C., Kim N. D., Fan X., Wang G., Peng Z., Hauge R. H., \& Tour J. M. "Growing Carbon Nanotubes from Both Sides of Graphene". ACS Appl. Mater. Interfaces 8, 7356-7362, 2016.

[35] Yan X., Cui X., Li B., \& Li L-S. "Large, Solution-Processable Graphene Quantum Dots as Light Absorbers for Photovoltaics”. Nano Lett. 10(5) 1869-1873. Doi:10.1021/nl101060h, 2010.

[36] Radich J. G., Dwyer R., \& Kamat P. V. " $\mathrm{Cu}_{2} \mathrm{~S}$ reduced graphene oxide composite for highefficiency quantum dot solar cells. Overcoming the redox limitations of $\mathrm{S}_{2}{ }^{-} \mathrm{S}_{\mathrm{n}}{ }^{2-}$ at the counter electrode". J. Phys. Chem. Lett. 2, 2453-2460. Doi:10.1021/jz201064k, 2011.

[37] Liu J. W., Wu J., Ahmad M. Z., Wlodarski W. "Hybrid aligned zinc oxide nanowires array on CVD graphene for hydrogen sensing". In 2013 Transducers \& Eurosensors XXVII: 17th International conference on Solid-State Sensors, Actuators and Microsystems (TRANSDUCERS \& EUROSENSORS XXVII) (Barcelona), 194-197, 2013.

[38] He Z., Hung P., Liu J., Thuch-Quyen N., \& Tan T. T. Y. "Understanding $\mathrm{TiO}_{2}$ size-dependent electron transport properties of a grpahene- $\mathrm{TiO}_{2}$ photoanode in dye-sensitized solar cells using conducting atomic force microscopy". Adv. Mater. 25, 6900-6904. Doi:10.1002/adma.201303327, 2013.

[39] Liu Y., Jin H., Zhu S., \& Yan D. “A facile method for fabricating $\mathrm{TiO}_{2} @$ mesoporous carbon and three-layered nanocomposites". Nanotechnology 23(32):325602, 2012.

[40] Khalil I., Julkapli N. M., Yehye W. A., Basirun W. J., \& Bhargava S. K. "Graphene-Gold Nanoparticles Hybrid-Synthesis, Functionalization, and Application in a Electrochemical and Surface-Enhanced Raman Scattering Biosensor". Materials 9, 406. Doi:10.3390/ma9060406, 2016.

[41] Wu B., Zhao N., Hou S., \& Zhang C. "Electrochemical Synthesis of Polyppyrrole, Reduced Graphene Oxide, and Gold Nanoparticles Composite and Its Application to Hydrogen Peroxide Biosensor". Nanomaterials 6, 220. Doi:10.3390/nano6110220, 2016.

[42] Lv Y., Wang F., Zhu H., Zou X., Tao C., \& Wang J. "Electrochemically Reduced Graphene Oxidenafion/Au Nanoparticle Modified Electrode for Hydrogen Peroxide Sensing". Nanomater Nanotechnol 6, 30. Doi: 10.5772/63519, 2016.

[43] Zhao Z., Zhang M., Chen X., Li Y., \& Wang J. "Electrochemical Co-Reduction Synthesis of AuPt Bimetallic Nanoparticles-Graphene Nanocomposites for Selective Detection of Dopamine in the Presence of Ascorbic Acid and Uric Acid". Sensors 15, 16614-16631. Doi: 10.3390/s150716614, 2015.

[44] Biroju R. K., Girl P. K., Dhara S., Imakita K., \& Fujii M. "Graphene-Assisted Controlled Growth of Highly Aligned ZnO Nanorods and Nanoribbons: Growth Mechanism and Phtoluminescence Properties". ACS Appl. Mater. Interfaces 6(1) 377-387. Doi:10.1021/am404411c, 2014.

[45] Wang Q., Guo X., Cai L., Cao Y., Gan L., Liu S., Wang Z., Zhang H., \& Li L. "TiO graphenes as efficient photoswitches with high oxygen sensitivity". Chem. Sci. 2, 1860-1864. Doi:10.1039/clsc00344e, 2011. 
INTERNATIONAL JOURNAL OF ENGINEERING TECHNOLOGY AND SCIENCES (IJETS) Vol.7 (1) June 2017 DOI: http://dx.doi.org/10.15282/ijets.7.2017.1.10.1072

[46] Meng X., Geng D., Liu J., \& Sun X. "Controllable Synthesis of Graphene-Based Titanium Dioxide Nanocomposites by Atomic Layer Deposition". Nanotechnology 22(16): 165602. Doi:10.1088/09574484/22/16/165602, 2011.

[47] Koay H. W., Ruslinda A. R., Ba Hashwan S. S., Fatin M. F., Thivina V., Tony V. C. S., Md Arshad M. K., Voon C. H., \& Hashim U. "Surface morphology of reduced graphene oxide-carbon nanotubes hybrid film for biosensing applications". IEEE-ICSE2016 Proc. 2016, Kuala Lumpur, Malaysia, 2016.

[48] Ding M. "Hybrid Materials Based on Carbon Nanotubes and Graphene: Synthesis, Interfacial Processes, and Applications in Chemical Sensing". Doctoral Dissertation, University of Pittsburgh, USA, 2013.

[49] Komori K., Terse-Thakoor T., Mulchandani A. "Bioelectrochemistry of Heme Peptide at Seamless Three-Dimensional Carbon Nnaotube/Graphene Hybrid Films for Highly Sensitive Electrochemical Biosensing". ACS Appl. Mater. Interfaces 7(6) 3647-3654. Doi: 10.1021/am508032p, 2015.

[50] Oh J. Y., Jun G. H., Jin S., Ryu H. J., \& Hong S. H. "Enhanced Electrical Networks of Stretchable Conductors with Small Fraction of Carbon Nanotube/Graphene Hybrid Fillers". ACS Appl. Mater. Interfaces 8(5) 3319-3325. Doi:10.1021/acsami.5b11205, 2016.

[51] Wu G.-H., Song X.-H., Wu Y.-F., Chen X.-M., Luo F., \& Chen X. "Non-enzymatic electrochemical glucose sensor based on platinum nanoflowers supported on graphene oxide". Talanta 105, 379385. Doi:10.1016/j.talanta.2012.10.066, 2013.

[52] Badhulika S., Paul R. K., Rajesh T. T., \& Mulchandani A. "Nonenzymatic glucose sensor based on platinum nanoflowers decorated multiwalled carbon nanotubes-graphene hybrid electrode". Electroanalysis 26, 103-108. Doi:10.1002/elan.201300286, 2014.

[53] ljeomah G., Obite F., \& Obaidiur R. "Development of carbon nanotube-based biosensors". Int. J. Nano and Biomaterials $\mathrm{X}(\mathrm{Y}) \mathrm{xxxx}$ [in press], 2015.

[54] Kang X., Wang J., Wu H., Aksay I. A., Liu J., \& Lin Y. "Glucose Oxidase-graphene-chitosan modified electrode for direct electrochemistry and glucose sensing". Biosens. Bioelectron. 25, 901905. Doi:10.1016/j.bios.2009.09.004, 2009.

[55] Palanisamy S., Cheemalapati S., \& Chen S.-M. "Amperometric glucose biosensor based on glucose oxidase dispersed in multiwalled carbon nanotubes/graphene oxide hybrid biocomposite". Mater. Sci. Eng. C Mater. Biol. Appl. 34, 207-213. Doi:10.1016/j.msec.2013.09.011, 2014.

[56] Hwa K.-Y., \& Subramani B. "Synthesis of zinc oxide nanoparticles on graphene-carbon nanotube hybrid for glucose biosensor applications". Biosens. Bioelectron. 62, 127-133. Doi:10.1016/j.bios.2014.06023, 2014.

[57] Ahmed I., Yazdani B., \& Zhu Y. "Recent Advances on Carbon Nanotubes and Graphene Reinforced Ceramics Nanocomposites". Nanomaterials 5, 90-114. Doi: 10.3390/nano5010090, 2015.

[58] Evans A. G. "Perspective on the development of high-toughness ceramics" J. Am. Ceram. Soc. 73, 187-206, 1990.

[59] Li J. "Mechanical and Electrical Characterization of Hybrid Carbon Nanotube Sheet-Graphene Nanocomposites for Sensing Applications". Doctoral dissertation, Embry-Riddle Aeronautical University, Daytona Beach, Florida, 2016. 
INTERNATIONAL JOURNAL OF ENGINEERING TECHNOLOGY AND SCIENCES (IJETS) Vol.7 (1) June 2017 DOI: http://dx.doi.org/10.15282/ijets.7.2017.1.10.1072

[60] Li T. "Improving the antistatic ability of polypropylene fibers by inner antistatic agent filled with carbon nanotubes". Comput. Sci. Tech. 64, 2089-2096, 2004.

[61] Chen T., \& Dai L. "Carbon nanomaterials for high-performance supercapacitors". Materials Today 16, 7-8, 2013.

[62] Yan B., Bin D., Ren F., Xiong Z., Zhang K., Wang C., \& Du Y. "Facile Synthesis of $\mathrm{MnPO}_{4} \cdot \mathrm{H}_{2} \mathrm{O}$ Nanowire/Graphene Oxide Composite Material and Its Application as Electrode Material for High Performance Supercapacitors". Catalysis 6, 198. Doi: 10.3390/catal6120198, 2016.

[63] Xue Y., Ding Y., Niu J., Xia Z., Roy A., Chen H., Qu J., Wang Z. L., \& Dai L. "Rationally designed graphene-nanotube 3D archtectures with a seamless nodal junction for efficient energy conversion and storage". Sci. Adv. 1:1400198, 2015.

[64] Dimitrakakis G. K., Tylianakis E., Froudakis E. "Pillared Graphene: A New 3-D Network Nanostructure for Enhanced Hydrogen Storage". Nano Lett. 8(10) 3166-3170. Doi:10.1021/nl801417w, 2008.

[65] Varshney V., Patnaik S. S., Roy A. K., Froudakis G., Farmer B. L. "Modelling of Thermal Transport in Pillared-Graphene Architectures". ACS Nano 4(2) 1153-1161. Doi:10.1021/nn901341r, 2010.

[66] Zhang L. L., Xiong Z., Zhao X. S. "Pillaring Chemically Exfoliated Graphene Oxide with Carbon Nanotubes for Photocatalytic Degradation of Dyes under Visible Light Irradiation". ACS Nano 4(11) 7030-7036. Doi:10.1021/nn102308r, 2010.

[67] Fan Z., Yan J., Zhi L., Zhang Q., Wei T., Feng J., Zhang M., Qian W., \& Wei F. "A threeDimensional Carbon Nanotube/Graphene Sandwich and Its Applications as Electrode in Supercapacitors". Adv. Mater. 22, 3723-3728, 2010.

[68] Velten J., Mozer A. J., Li D., \& Zakhidov A. "Nanocomposite as efficient counter electrodes in dye-sensitized solar cells". Nanotechnology 23, 085201 (6pp). Doi:10.1088/0957-4484/23/8/085201, 2012.

[69] Tsai C.-H., Chen C.-H., Hsiao Y.-C., \& Chuang P.-Y. "Investigation of graphene nanosheets as counter electrodes for efficient dye-sensitized solar cells" Org. Electron. 17, 57-65. Doi:10.1016/j.orgel.2014.11.016, 2015.

[70] Yang N., Zhai J., Wang D., Chen Y., \& Jiang L. “Two-dimensional graphene bridges enhanced photo induced charge transport in dye-sensitized solar cells". ACS Nano 4, 887-894. Doi:10.1021/nn901660v, 2010.

[71] Madhavan A. A, Kalluri S., Chacko D. K., Arun T. A., Nagarajan S., Subramanian K. R.V., Nair A. S., Nair S. V., \& Balakrishnan A. "Electrical and optical properties of electrospun $\mathrm{TiO}_{2}$-graphene nanofibers and its application as DSSC photo-anodes". RSC Adv. 2, 13032-13037. Doi:10.10.1039/c2ra22091a, 2012.

[72] Yen M.-Y., Hsiao M.-C., Liao S.-H., Liu P.-I, Tsai H.-M., Ma C.-C. M, Pu N.-W., \& Ger M.-D. "Preparation of graphene/multi-walled carbon nanotube hybrid and its use as photoanodes of dyesensitized solar cells". Carbon 49, 3597-3606, 2011.

[73] Hoshi H., Tanaka S., \& Miyoshi T. "Pt-graphene electrodes for dye-sensitized solar cells". Mater. Sci. Eng. B Adv. Funct. Solid State Mater. 190, 47-51. Doi:10.1016/j.mseb.2014.09.003, 2014. 
[74] Son D. I., Kwon B. W., Yang J. D., Park D. H., Seo W. S., Lee H., Yi Y., Lee C. L., \& Choi W. K. "Charge Separation and Ultraviolet Photovoltaic Conversion of $\mathrm{ZnO}$ Quantum Dots Conjugated with Graphene Nanoshells". Nano Res. 5(11): 747-761, 2012.

[75] Li S., Luo Y., Lv W., Yu W., Wu S., Hou P., Yang Q., Meng Q., Liu C., Cheng H.-M. "Vertically Aligned Carbon Nanotubes Grown on Graphene Paper as Electrodes in Lithium-Ion Batteries and Dye-Sensitized Solar Cells". Adv. Energy Mater. 1, 486-490, 2011.

[76] Zheng H., Neo C. Y., Ouyang J. "Highly efficient iodide/triiodide dye sensitized solar cells with gel-coated reduce graphene oxide/single-walled carbon nanotube composites as the counter electrode exhibiting an open-circuit voltage of 0.90V"'. ACS Appl. Mater. Interfaces 5, 6657-6664. Doi:10.1021/am401392k, 2013.

[77] Wang K., Wan S., Liu Q., Yang N., \& Zhai J. "CdS quantum dot decorated titania/graphene nanosheets stacking structures for enhanced photoelectrochemical solar cells". RSC Adv. 3, 2375523761. Doi:10.1039/c3ra43770a, 2013.

[78] Liu M., Li G., \& Chen X. "One-pot Controlled Synthesis of Sponglike CulnS 2 Microspheres for Efficient Counter Electrode with Graphene Assistance in Dye-Sensitized Solar Cells". ACS Appl. Mater. Interfaces 6(4) 2604-2610. Doi:10.1021/am405100g, 2014.

[79] Zhang X., Zhang H., Lin Z., Yu M., Lu X., \& Tong Y. "Recent advances and challenges of stretchable supercapacitors based on carbon materials". Sci. China Mater 59(6) 475-494, 2016.

[80] Dembele K. T., Selopal G. S., Soldano C., Nechache R., Rimada J. C., Concina I., Sberveglieri G., Rosei F., \& Vomiero A. "Hybrid Carbon Nanotubes-TiO, Photoanodes for High Efficiency DyeSensitized Solar Cells". J. Phys. Chem. C, 117, 14510-14517, 2013.

[81] Li Z. R., Kunets V. P., Saini V., Xu Y., Dervishi E., Salamo G. J., Biris A. R., \& Biris A. S. "Lightharvesting using high density $p$-type single wall carbon nanotube/n-type silicon heterojunctions". ACS Nano 3, 1407-1414, 2009. 
INTERNATIONAL JOURNAL OF ENGINEERING TECHNOLOGY AND SCIENCES (IJETS) Vol.7 (1) June 2017 DOI: http://dx.doi.org/10.15282/ijets.7.2017.1.10.1072 